\title{
Photodynamic therapy for the treatment of atherosclerotic plaque: Lost in translation?
}

\author{
Manish Jain $^{1}$ | Matthieu Zellweger ${ }^{2}$ | Georges Wagnières ${ }^{2}$ | Hubert van den Bergh ${ }^{2}$ | \\ Stéphane Cook ${ }^{1}$ | Marie-Noelle Giraud ${ }^{1}$
}

${ }^{1}$ Cardiology, Department of Medicine, University and Hospital of Fribourg, Fribourg, Switzerland

${ }^{2}$ Medical Photonics Group, LCOM-ISIC, Swiss Federal Institute of Technology (EPFL), Lausanne, Switzerland

Correspondence

Marie-Noelle Giraud, Département de médecine- Chaire de Cardiologie, Université de Fribourg- Faculté des sciences, Fribourg, Switzerland.

Email: marie-noelle.giraud@unifr.ch

Funding Information

This work was supported by the Swiss

National Science Foundation (Grant 150271).

\begin{abstract}
Summary
Acute coronary syndrome is a life-threatening condition of utmost clinical importance, which, despite recent progress in the field, is still associated with high morbidity and mortality. Acute coronary syndrome results from a rupture or erosion of vulnerable atherosclerotic plaque with secondary platelet activation and thrombus formation, which leads to partial or complete luminal obstruction of a coronary artery. During the last decade, scientific evidence demonstrated that when an acute coronary event occurs, several nonculprit plaques are in a "vulnerable" state. Among the promising approaches, several investigations provided evidence of photodynamic therapy (PDT)-induced stabilization and regression of atherosclerotic plaque. Significant development of PDT strategies improved its therapeutic outcome. This review addresses PDT's pertinence and major problems/challenges toward its translation to a clinical reality.
\end{abstract}

\section{KEYWORDS}

Atherosclerosis, Laser, Photodynamic therapy, Photosensitizers, Restenosis, Theranostic

\section{1 | INTRODUCTION}

Coronary atherosclerosis is a multifactorial disease process with two distinct periods. The first period is plaque growth, which is long-lasting and mostly asymptomatic. During this period, the plaque evolves gradually from the "fatty streak" to the advanced plaque under the influence of well-known "risk factors." The second period is variable in both duration (some patients die after the first plaque rupture) and its symptomatology (some ruptures remain silent): this is the "vulnerable" period. $^{1,2}$

Identification and treatment of acute coronary syndromes have drastically evolved during the last two decades. Accordingly, the shortterm outcome of patients suffering from acute coronary syndrome has significantly improved during this short period. However, coronary heart disease still causes one in every six deaths in industrialized countries. ${ }^{3}$ Indeed, clinical outcome at 1 year is affected by recurrent myocardial infarction and death in $10 \%-15 \%$ of patients. ${ }^{3}$ Previous studies using angioscopy suggested that delayed plaque healing, persistent thrombus, and recurrent plaque rupture are main mechanisms for lesion progression and associated clinical complications. In particular, $40 \%-80 \%$ patients with ACS have more than one ruptured plaque, which are frequently left untreated and therefore may contribute to long-term adverse clinical outcomes. Some convincing preventive approaches arose from cholesterol-lowering (such as "statins") or cholesterol-modulating agents (as recombinant apolipoprotein A1Milano). In the PROVE IT-TIMI 22 trial, $22.4 \%$ of patients experienced a coronary event during 2 years of intensive statin therapy ${ }^{4,5}$; nevertheless, the hospitalization rates stayed the same. ${ }^{6}$

Percutaneous coronary intervention ( $\mathrm{PCl}$ ) with stent implantation is the most commonly used procedure; however, these techniques are also associated with periprocedural infarction ( $0.17 \%)$, stent thrombosis ( 1.27\%), and in-segment restenosis resulting from intimal hyperplasia or vessel remodeling. ${ }^{7,8}$ Patients with blockage of two or three coronary arteries are generally considered for bypass surgery. ${ }^{9}$ Nevertheless, bypass procedures may be of limited value in vessels with diffused distal disease. Initial data regarding laser-induced 


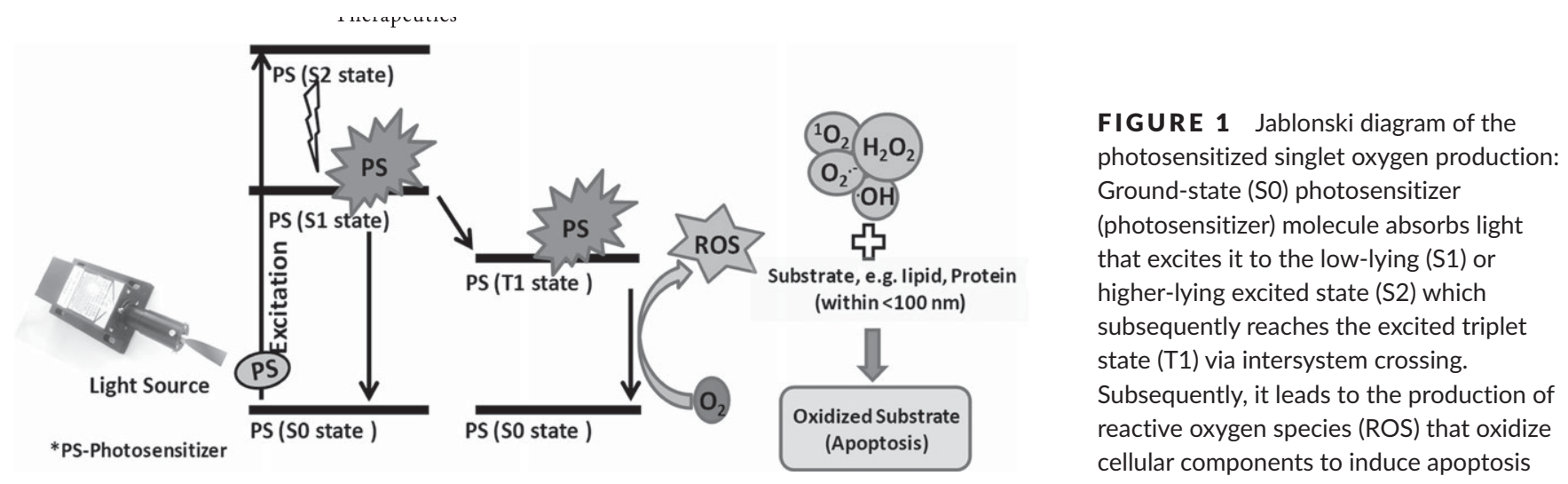

vaporization of plaque demonstrated technical success; however, subsequent studies demonstrated the importance of the type of the lesion or patient factors in determining the outcome of laser-induced percutaneous intervention. ${ }^{10} \mathrm{New}$ therapeutic approaches of the identification and treatment of the vulnerable plaque are emerging. Among them, PDT presents a promising alternative for atherosclerosis treatment. ${ }^{11}$ PDT has been shown to eradicate inflammatory cells and promote plaque stabilization, vascular healing, and debulking of the plaque. $^{12}$

\section{2 | PDT PRINCIPLE}

The photosensitizer can absorb light from a ground singlet electronic state, indicated as SO, to a low-lying electronically excited singlet state called S1 (Figure 1). Optical absorption of a more energetic photon (this time in the blue/violet part of the spectrum) may also take place to a higher-lying, more energetic, electronically excited singlet state, here labeled as S2. The S2 state often tends to undergo a process called internal conversion, where it becomes a highly vibrationally excited S1 state, which then rapidly loses its excess vibrational energy to become S1 without the non-Boltzmann excess vibrational energy. The S1 state now can, depending on the photosensitizer, either fluoresce back down to the SO ground state or mainly undergo intersystem crossing to the lowest triplet state of the photosensitizer labeled as T1. The former photosensitizer will be mainly used for detection, the latter mainly for therapeutic purposes.

The T1 triplet states produced are metastable that undergo collision with ground-state triplet molecular oxygen. In this collision, the triplet photosensitizer may return to its singlet ground state, whereas the triplet ground-state oxygen molecule will then be excited to its lowest singlet electronically excited state. The newly produced singlet oxygen molecules are very reactive, and they go about oxidizing the molecules in their direct surroundings, for instance, by insertion into $\mathrm{C}-\mathrm{H}$ bonds. This implies that the oxidizing damage is very local, that is, very close (tens of $\mathrm{nm}$ ) from where the photosensitizer is localized. Reaction with the photosensitizer itself can lead to the photobleaching of the photosensitizer. Other reactive oxygen species (ROS) may be produced in these oxidative cascades, including the superoxide anion $\left(\mathrm{O}_{2}^{-}\right)$, hydroxyl radicals $\left({ }^{\circ} \mathrm{OH}\right)$, and hydrogen peroxide $\left(\mathrm{H}_{2} \mathrm{O}_{2}\right)$. ROS production induced a chain of cytotoxic event such as loss of

mitochondrial membrane potential, lipid peroxidation, and protein denaturation of cellular membranes and organelles. ${ }^{13}$

\section{3 | MECHANISM OF ACTION}

The main role of PDT in the treatment of atherosclerotic plaque is to generate ROS that will interfere with cell survival and consequent remodeling process. Primarily, PDT-mediated ROS generation inducing cell death is dependent on the type of cell, photosensitizing agent and its cellular localization, and the light dose. However, if light dose and target tissue are kept constant, PDT-mediated cell death is dependent on the type of photosensitizer and its subcellular localization. Interestingly, a particular photosensitizer can get localized in more than one organelle resulting in the concurrent activation of more than one cell death pathways. ${ }^{14}$

Pathways of this PDT-induced cell death are briefly discussed here (Figure 2). Two distinct cell death pathways after photosensitization can be recognized, that is, programmed (apoptotic and autophagy) pathways and nonprogrammed (necrosis) pathways. Apoptosis is often likened to cell suicide and is induced by chemical signaling from within and/or from outside of the cell. The process is well regulated and ends with the components of the destroyed cell being prepared in such a way so that they can be consumed by neighboring cells and macrophages so as to limit inflammation of the tissue. Necrosis on the other hand is a much more catastrophic process in which the plasma membrane is punctured, the contents of the cell spill out, and inflammation likely follows. Generally, apoptotic pathway predominates at low light intensity, while necrotic pathway is activated at higher light doses. PDT may also stimulate autophagy, a self-degradative process that delivers cytoplasmic constituents to the lysosome. ${ }^{15}$ A double-membrane structure called autophagosome surrounds the target region, creating a vesicle that separates its contents from the rest of the cytoplasm. Damaged lysosomes then fuse with autophagosomes to hydrolyze damaged organelles and recycle them during autophagy. ${ }^{14}$

When the photosensitizer is located in the mitochondria, PDT leads to a chain of processes that result in the release of mediators such as Bcl-2 proteins BAX and BAK and promotes the release of cytochrome $\mathrm{c}$ to the cytosol. The released cytochrome $\mathrm{c}$ binds to apoptosis activating factor 1 (APAF-1) and initiate the activation of the caspases. These active caspases cleave numerous proteins such as nuclear 
FIGURE 2 Overview of the cell death pathways associated with PDT: PDTinduced cell death occurs by different pathways. (1) Mitochondrial pathway release of cytochrome $c$ and activation of caspases. (2) Activation of death receptors (FAS, TNF) activates caspase-8. (3) Endoplasmic reticulum pathway release of $\mathrm{Ca}^{++}$. (4) Lysosomal pathway formation of autophagosome, inhibition of mTOR complex, may promote or inhibit the process of apoptosis. In addition, PDT may lead to necrosis if the light dose is sufficiently high

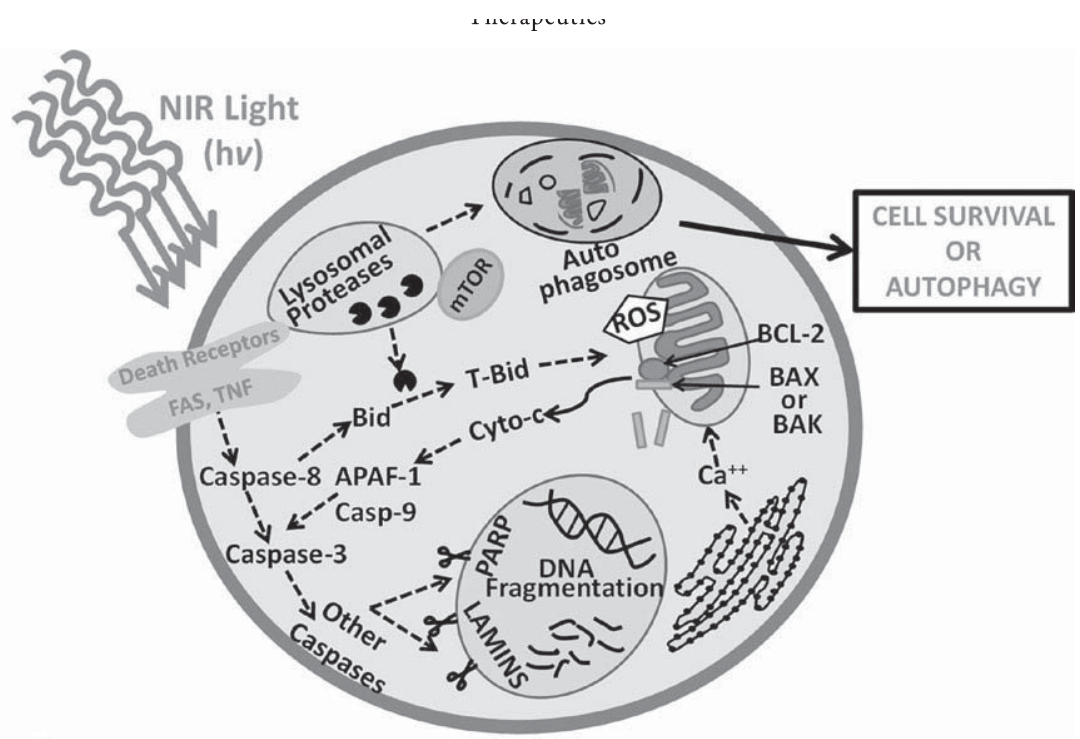

Different Cellular localization of photosensitizer and the light dose
Mitochondria, Lysosomal or endoplasmic reticulum localization, damage to $\mathrm{Bcl}-2$ proteins, release of cytochrome $\mathrm{c} / \mathrm{Ca}^{++}$, caspase activation
APOPTOSIS lamins or poly(ADP-ribose) polymerase (PARP) leading to nuclear breakdown, DNA fragmentation, or inhibition of DNA repair resulting in apoptosis (Figure 2). Granville DJ et al., using verteporfin, showed that PDT induces cellular redistribution of mitochondrial cytochrome $\mathrm{c}$, apoptosis-inducing factor levels, proapoptotic $\mathrm{Bcl}-2$ family member Bax, and the subsequent activation of multiple caspases during PDTinduced smooth muscle cell apoptosis. ${ }^{16}$ Likewise, Chen et al. ${ }^{13}$ using murine macrophages and human saphenous vein SMCs showed that motexafin lutetium is mainly localized within the lysosomes and endoplasmic reticulum; however, it also localizes, to a lesser extent, within the mitochondria. Subsequent PDT results in the loss of mitochondrial membrane potential, mitochondrial release of cytochrome c, and activation of caspases that trigger redox-sensitive apoptosis of vascular cells and macrophages.

When a photosensitizer is localized in lysosomes, PDT leads to release of proteolytic enzymes which can cause induction of apoptosis by cleaving proapoptotic factor BID to form truncated BID (tBID) which then translocates to the mitochondria to promote the oligomerization of BAX and BAK (Figure 2). PDT induces autophagy through modifications of essential genes in the pathway including mTOR (mammalian target of rapamycin) or JNK (c-Jun N-terminal kinases). Depending on the severity of oxidative injury, PDT-induced autophagy may thus either act in a cytoprotective manner or can induce cell death by damaging lysosomes and endosomes.

Another example, shown in Figure 2, is the photodynamic activation of the "cell-death-inducing complexes" at the plasma membrane which induces caspase-8, and in turn the release of caspase- 3 , which can finally also lead to induction of apoptosis via interaction with the mitochondria. Examples of such cell-surface-localized death receptors are the proteins of the tumor necrosis factor receptors and Fas. ${ }^{17}$ Such modification in plasma membrane can lead to alterations in membrane functions such as metabolism and cell signaling, resulting ultimately in cell death. PDT can also predominantly induce autophagy or necrosis when the apoptotic pathway is dysfunctional.

Photodynamic therapy-induced damage to the endoplasmic reticulum can stimulate the release of $\mathrm{Ca}^{++}$which in turn can cause apoptosis via interaction with the mitochondria. Lastly, PDT could also induce a protective innate immune response by stimulating the release of cytokines and growth factors that contribute to the increased uptake of PDT-killed cells by dendritic cells, accompanied by their phenotypic maturation, enabling their interaction with PDT-treated cells as well as subsequent T-cell responses. ${ }^{18}$

\section{4 | PDT FOR ATHEROSCLEROSIS}

In the last decade, porphyrins, chlorines, or dye-based photosensitizers were tested for the treatment of atherosclerotic plaques (Table 1). Most of the porphyrin-based photosensitizers have demonstrated selective accumulation within atherosclerotic plaques. One of the often-given explanations is that the injected porphyrins rapidly associate themselves with blood proteins, mainly low-density lipoprotein. Allison et al. ${ }^{19}$ observed enhanced uptake selectivity of benzoporphyrin derivative in the atherosclerotic plaque of rabbits by preassociating benzoporphyrin derivative with low-density lipoprotein.

In 1983, Spears et al. ${ }^{20}$ demonstrated selective uptake of porphyrin mixture, formally named as hematoporphyrin derivative in atheromatous plaques of Erythrocebus patas monkey, while no fluorescence could be demonstrated in aortic segments free of plaque. This selective accumulation of hematoporphyrin derivative has been confirmed 

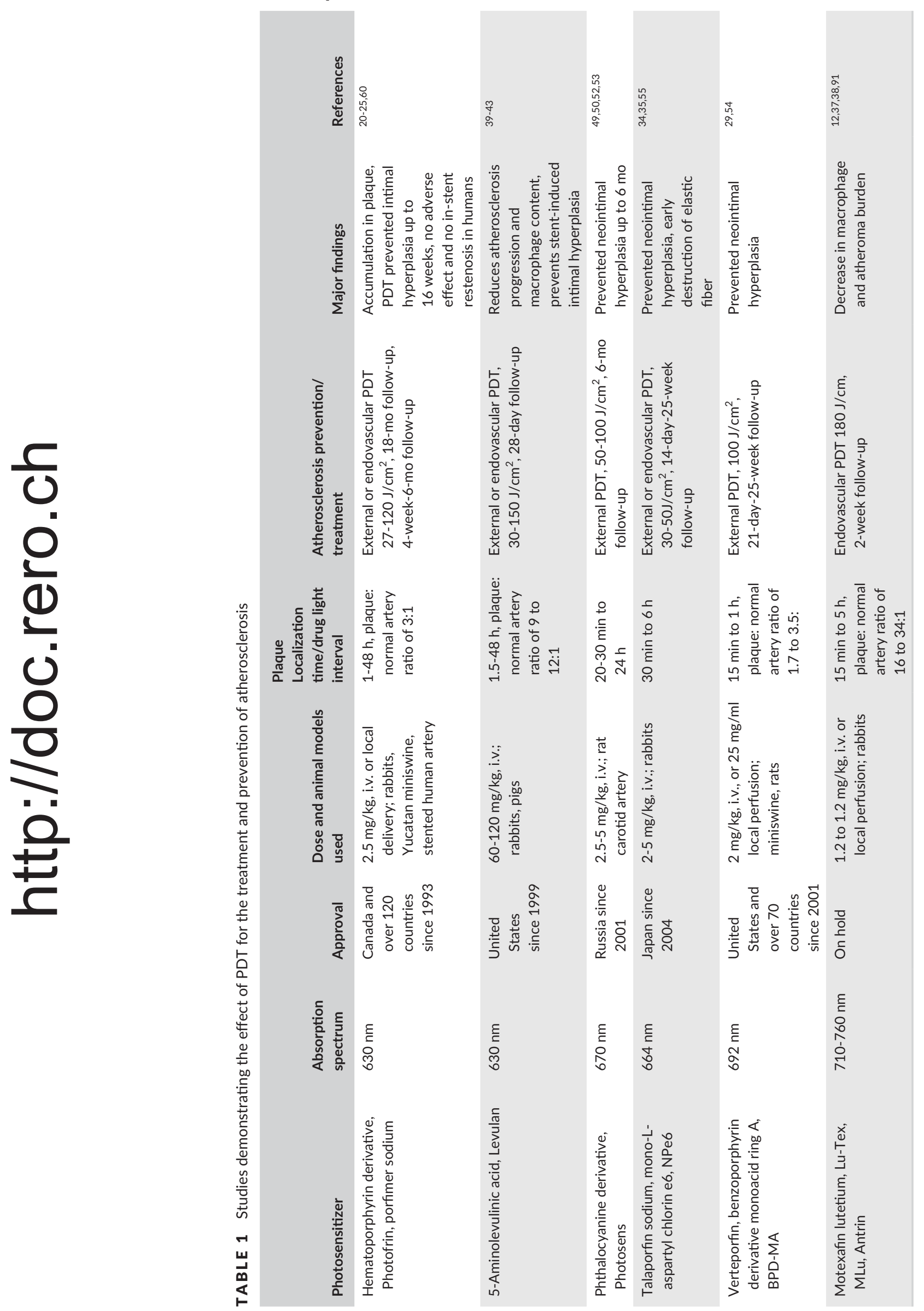
in rabbit atherosclerosis model where hematoporphyrin derivative fluorescence was observed throughout the thickness of the plaque, and its intensity followed a concentration gradient from the luminal surface toward aortic wall. ${ }^{21,22}$ Hematoporphyrin derivativeassociated PDT inhibits smooth muscle cell growth and decreases intima/media ratio of rabbit atheroma 7 days (0.33) or 14 days (0.72) post-PDT as compared with controls (2.27). ${ }^{22}$ Photofrin, derived from hematoporphyrin derivative, exhibited similar trends in preclinical $^{23-26}$ studies; however, cutaneous photosensitivity in human subjects $^{27,28}$ and inadequate penetration of the 630-nm light through the endoluminal blood are major drawbacks. Therefore, other photosensitizers namely verteporfin, phthalocyanine derivatives, namely copper phthalocyanine tetrasulfonate, chloroaluminum-sulfonated phthalocyanine and aluminum-disulfonated phthalocyanine, and talaporfin sodium were developed and tested for atherosclerosis/ restenosis.

Verteporfin, also referred to as benzoporphyrin derivative monoacid ring A (BPD-MA), is a potent, second-generation photosensitizer derived from hematoporphyrin. Verteporfin binds with endogenous low-density lipoproteins and induces apoptosis upon light activation by increasing mitochondrial cytochrome $\mathrm{c}$ and apoptosis-inducing factor levels. ${ }^{16}$ BPD-MA was found to be taken up by atherosclerotic plaque of Watanabe heritable hyperlipidemic rabbits, humans, and miniswine. ${ }^{19,29}$ Ratios of BPD-MA recovered in the atheromatous tissue divided by that recovered in the normal arterial tissue were found to be $1.7: 1$ to $3.5: 1 .^{19}$

Phthalocyanine derivatives represent a class of tetraazaisoindole pigments and were initially proposed for PDT of cancer. A study conducted by Eldar et al. ${ }^{30}$ proved preferential uptake of a water-soluble copper phthalocyanine tetrasulfonate by atherosclerotic plaques in rabbits. However selectivity of the dye in the atheromatous plaques was only 2.6 times higher than in the normal vessel wall. It has also been shown that two-photon excitation of the photosensitizer can induce phototoxicity in Jurkat cells. ${ }^{31}$ However, the use of phthalocyanines in the PDT of atherosclerosis is restricted by slow clearance rate and poor aqueous solubility and tendency of metallophthalocyanines to aggregate in aqueous buffer at physiological $\mathrm{pH}$.

Talaporfin sodium is a water-soluble photosensitizer consisting of chlorin e6 used since 2004 in Japan for malignant brain tumors. ${ }^{32}$ It is also a potent fluoroprobe tool to visualize the atherosclerotic lesions in beating heart of rabbit small coronary arteries. ${ }^{33}$ It also distributes selectively in the atherosclerotic plaques of rabbits. ${ }^{34,35}$

Motexafin lutetium is another water-soluble photosensitizer developed by Pharmacyclics Inc. with great PDT efficiency and minor cutaneous phototoxicity. Its longer wavelength for photoactivation $(732 \mathrm{~nm})$ reduces attenuation of light energy by blood and tissues. Motexafin lutetium primarily distributes with the low-density lipoprotein (LDL)-cholesterol fraction after intravascular injection in diseased animal models. Retention ratio following intravenous treatment was $16: 1$ to $34: 1$ between atheromatous plaque and normal aortic wall. ${ }^{12,36-38}$

5-Aminolevulinic acid (5-ALA) (Levulan ${ }^{\circledR}$; DUSA Pharmaceuticals, Wilmington, MA, USA) is a naturally occurring precursor of
protoporphyrin-IX. Several studies conducted in rabbits ${ }^{39,40}$ and pigs ${ }^{41,42}$ established efficacy of 5-ALA-based PDT in prevention and treatment of atherosclerotic plaque. 5-ALA-induced protoporphyrin-IX was concentrated in plaque 9-fold compared to the normal adjacent aortic wall. Endovascular illumination via cylindrical light diffuser resulted in a significant reduction in plaque without damage to the medial wall. ${ }^{43}$

\section{5 | ROLE OF PDT IN PLAQUE STABILIZATION}

Photodynamic therapy, using conventional photosensitizers, has been carried out "in vitro" on most of the cell types including general macrophages, ${ }^{13,44,45}$ M1 and M2 macrophages, ${ }^{46}$ smooth muscle cells, ${ }^{13,16,47}$ endothelial cells, ${ }^{47}$ and fibroblasts. ${ }^{47}$ The "in vitro" PDT was phototoxic to essentially all these cell types, and PDTinduced changes were sufficiently complex. It is important to note that in atherosclerosis, a subset of macrophages, that is, M2 macrophages, endothelial cells, and smooth muscle cells, are known to contribute in plaque stabilization and their depletion could make plaque more vulnerable to rupture. It is therefore reasonable to question that PDT may have deleterious effect on certain type of macrophages.

It is a paradox that PDT, which inherently causes injury to almost all the cell types of the plaque, still provokes plaque stabilization perhaps by inducing a sustained decrease in plaque macrophage and foam cell content. ${ }^{11,12,39}$ Evidences have been obtained from several experimental studies. Hayase et al. ${ }^{12}$ showed that motexafin lutetiumbased PDT results in a significant decrease in macrophage and atheroma burden without damage to the normal vessel wall. These findings were further confirmed by Waksman et al. ${ }^{11}$ who observed that PDT with a new photosensitizer, MV0611, destroyed plaque macrophages without damaging the structural integrity of the vessel. Associated with macrophage depletion, repopulation of plaques with a nonproliferating smooth muscle cells stabilized the plaque. ${ }^{11}$ In addition, Peng et al. demonstrated that 5-aminolevulinic-acid-mediated PDT reduces the macrophage by $64 \%$ and induces collagen content by $44 \%$ after 4 weeks of PDT in rabbit model. The study pointed out that smooth muscle cell content was initially reduced $(24 \%)$ at 1 week, and that subsequently increased (18\%) at 4 weeks of PDT. ${ }^{39}$ Complex interactions between cells, growth factors, and extracellular matrix are responsible for such a favorable effect. ${ }^{48}$ The mechanisms of this PDT effect on the vascular wall were shown by LaMuraglia GM and colleagues who described that exposure of rat carotid artery to PDT reduces basic fibroblast growth factor content and significantly reduces the smooth muscle cell mitogenesis by $52 \%$ after cellular injury. ${ }^{48}$ Based on these preclinical findings, PDT could be utilized for plaque stabilization or regression. Still further studies are warranted using models closer to human coronary atherosclerosis that must evaluate appropriate dosage, light hypersensitivity, and possibility of photosensitization interference with arterial calcification and antiplatelet/lipid-lowering drugs. 


\section{6 | PDT FOR PREVENTING RESTENOSIS}

Experimental evidence suggests that PDT, in addition to plaque stabilization and regression, can also be applied to prevent restenosis. ${ }^{42,49,50}$ Restenosis is provoked by endothelial or medial injury followed by inflammatory cell infiltration, vascular smooth muscle cell (VSMC) proliferation, and migration resulting in intimal hyperplasia and narrowing of vessel lumen. PDT leads to inactivation of basic fibroblast growth factor and thus inhibits smooth muscle cell proliferation and promotes eradication. ${ }^{51}$ PDT-mediated inhibition of matrix-associated transforming growth factor beta, inducer of endothelial cell apoptosis, stimulates endothelial cell growth. ${ }^{48}$ As such, PDT contributes to positive environment that facilitates endothelialization and opposes smooth muscle cell proliferation and migration thereby preventing neointimal hyperplasia.

It has been shown that chloroaluminum-sulfonated phthalocyanine-associated PDT reduced intimal hyperplasia following balloon injury in rat carotid arteries. ${ }^{49}$ LaMuraglia GM et al. further reported that intravenous injection of chloroaluminum-sulfonated phthalocyanine $(5 \mathrm{mg} / \mathrm{kg}$ ) at the time of balloon injury followed by PDT (100 J/ $\mathrm{cm}^{2}$ ) could prevent intimal hyperplasia up to 16 weeks. ${ }^{50,52}$ Further, Nyamekye I et al. showed that PDT $\left(50 \mathrm{~J} / \mathrm{cm}^{2}\right)$ with aluminumdisulfonated phthalocyanine inhibits intimal hyperplasia up to 6 months in rat carotid arteries. ${ }^{53}$ In rabbit model, Wakamatsu et al. using talaporfin sodium showed that endovascular PDT even at low light dose $\left(10 \mathrm{~J} / \mathrm{cm}^{2}\right)$ led into complete depletion of smooth muscle cells after 2 days, which ultimately prevented intimal hyperplasia at 14 days after PDT. ${ }^{34}$ Likewise in rat and rabbit balloon injury model, local delivery and subsequent photoactivation via external irradiation inhibit the development of intimal hyperplasia. ${ }^{54,55}$ Importantly, PDT is a progressive, biochemical process that may last for several days. Reendothelialization of PDT-treated arteries has been reported to be complete by 14 days, ${ }^{42}$ while repopulation of the media is delayed. ${ }^{56}$ This beneficial PDT effect was however found to be dependent on the treatment field, and it is very important to treat whole injured artery and/or we should include a part of an uninjured artery for effective PDT prevention. ${ }^{50}$ These available nonclinical data highlighted PDT to be a safe and effective therapeutic alternative for the management of restenosis.

\section{7 | CLINICAL STUDIES}

Clinical trials were conducted to establish the safety and efficacy of PDT for the prevention of restenosis. The first clinical trial of adjuvant arterial PDT to prevent restenosis following angioplasty was reported by Jenkins et al. in 1999. The therapeutic potential of 5-ALA was investigated in seven patients undergoing second femoral angioplasty after symptomatic restenosis or occlusion within 2-6 months of the intervention. ${ }^{57}$ This study suggested that endovascular PDT is safe and may reduce restenosis following angioplasty, while no evidence of clinical restenosis was observed during the 6-month follow-up.
Photoangioplasty with motexafin lutetium was subsequently investigated in phase I and II trials. ${ }^{58}$ The first included 47 patients with symptomatic atherosclerotic peripheral arterial insufficiency. ${ }^{58}$ The patients received a single i.v. dose of motexafin lutetium around 24 hours before the percutaneous intervention. Intravascular ultrasonography was performed before and after the procedure. Laser light energy was delivered through a 3 -cm-long cylindrical optical light diffusing fiber at the fixed wavelength of $730 \pm 6 \mathrm{~nm}$. This study confirmed the safety of motexafin lutetium-based PDT with no evidence of embolization, vascular trauma, or disease progression. The second one was conducted in 75 patients undergoing $\mathrm{PCl}$ and stent deployment and was based on a follow-up of 6 months. This trial confirmed the safety of motexafin lutetium-based PDT as an adjunct to $\mathrm{PCl}$ and also defines the range for selection of optimal drug and light dose regimens to be used in combination. ${ }^{59}$

Photofrin-PDT was evaluated to reduce the recurrence of restenosis in human subjects. Photofrin was locally delivered for $10 \mathrm{~min}$ utes to coronary-stent-implanted lesions using a local delivery balloon catheter in five patients. ${ }^{60}$ PDT was performed by inserting a laser catheter into the stent lesion at the time of coronary-stent placement. Eighteen-month follow-up after PDT showed no major adverse effect (myocardial infarction, coronary artery spasm, thrombosis, dissection, or aneurysmal dilatations) and no in-stent restenosis.

Taking together, these clinical studies established PDT, when used in conjunction with $\mathrm{PCl}$ procedures, as a safe and efficacious tool for preventing the occurrence of restenosis. Large clinical studies are still needed to evaluate the efficacy of PDT in these specific indications.

\section{EX VIVO AND IN VIVO ANIMAL MODELS FOR PDT}

"In vivo" studies have been carried out in different animal models, including rats, rabbits, miniswine, and monkeys, to investigate the optimal selective photodynamic activity of the photosensitizer. Several studies documented the beneficial effect of PDT in terms of plaque stabilization or even regression using rabbits or swine as an animal model. ${ }^{11,12,22,23,26,41,61-63}$ In most of the cases, rabbits were maintained with cholesterol-rich diets. Furthermore, to induce advanced lesions a combination of atherogenic diet and mechanical balloon injury in aorta or iliac arteries was performed. Although most of the tested photosensitizers demonstrated preferential accumulation within the plaque, it is noteworthy that atherosclerotic plaques in rabbits are composed of high smooth muscle cell content and macrophage-derived foam cells with some fibrous components ${ }^{64,65}$ and these lesions are not similar to atherosclerotic plaques found in human coronary artery. ${ }^{11}$ Human coronary plaques are often characterized as lipid-rich plaques containing a lipid core and fibrous plaques rich in collagen fibers but poor in macrophages. Larger animal models such as cholesterol-fed swine model show similarity to humans with respect to size of the coronary artery as well as in the development and progression of coronary lipid core-containing atherosclerotic lesions. Coronary artery of large pigs ${ }^{41,62}$ or aorta of 


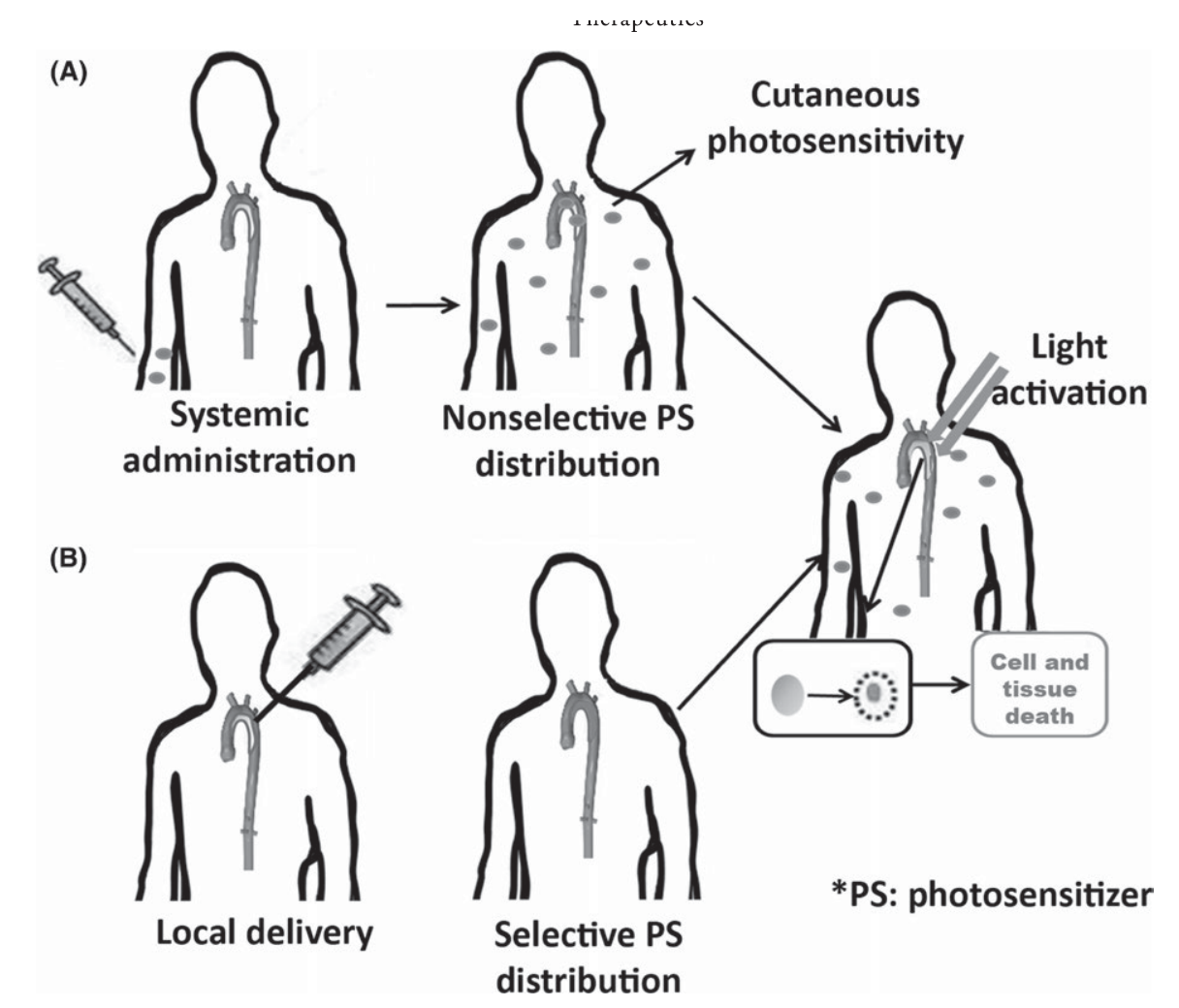

FIGURE 3 Intravascular delivery: (A) PDT generally involves systemic delivery of photosensitizer that besides accumulating at the target site also accumulates in nontarget sites leading to adverse side effects. (B) Local delivery facilitates the accumulation of photosensitizer entirely in the target tissue avoiding systemic side effects

Systemic administration

(B)

\section{distribution}

minipigs ${ }^{23,63}$ was commonly employed to study the efficacy of PDT on restenosis.

It is important to realize that atherosclerotic plaques at different vascular sites vary greatly between the size, rate of growth, and plaque composition. Such differences can greatly influence biodistribution of the photosensitizer, light absorption, and scattering that can drastically influence the PDT efficacy. It is therefore mandatory for investigators to use multiple approaches for the translation of findings in animals to the human atherosclerosis. Interventions demonstrating PDT efficiency in terms of plaque stabilization/regression in animal models should be interpreted with considerable caution with respect to their predictive value for humans.

\section{9 | SELECTIVE DRUG DELIVERY}

Delivery of soluble photosensitizer has mostly been performed via intravenous injections. Following intravenous injection, photosensitizers accumulate over time within the atherosclerotic lesions. Nevertheless, accumulation in skin has been observed, leading to inconvenient cutaneous photosensitivity such as erythema and edema that may last up to 3 months. ${ }^{66}$ Novel delivery strategies have been developed to minimize side effects.

Nanotechnologies: Nanoparticles with excellent tissue penetration ability, good absorption, and sustained release are attractive approaches for selective delivery of the photosensitizer within atherosclerotic plaques. ${ }^{67}$ It has also been shown that enzymatic crosslinking or conjugation of a photosensitizer with a ligand/vector, which specifically binds to cell-surface receptor such as class A scavenger receptors ${ }^{68}$ or dextran receptors (SIGNR1) ${ }^{67}$ present on macrophages, improves the recognition specificity and targeting ability of photosensitizer. SIGNR1 is a C-type lectin expressed at high levels on macrophages and mediates the uptake of dextran polysaccharides. ${ }^{69,70}$ Cross-linked dextran-coated iron oxide nanoparticle provided 600fold efficacy in the destruction of plaque macrophages and substantially reduced skin phototoxicity as compared to conventional photosensitizers. Furthermore, ALA associated with gold nanoparticles has shown increased specificity to atherosclerotic plaques. ${ }^{71}$

Liposomes: Liposomes increased the retention and the highly efficient and specific delivery of the $\mathrm{Zn}$ (II)-phthalocyanine within the macrophages of atherosclerotic lesions. ${ }^{72}$ Liposome-based formulation has been tested as delivery vehicle for accumulation of verteporfin within atherosclerotic plaques of rabbits. ${ }^{19}$ For clinical use, verteporfin has a liposomal-delivered formulation (Visudyne ${ }^{\mathrm{Tm}}$; Novartis). However, the physicochemical properties of photosensitizing agents, such as extreme hydrophilicity or lipophilicity and high molecular weights, make this complicated.

Intravascular delivery: The exposure of the plaque for a short while to a high concentration of the photosensitizer presents several advantages. The possibility to decrease the dose and time of exposure ${ }^{73}$ and the reduction in systemic side effects have fostered the development of local drug delivery balloon catheters. A schematic representation of local and systemic delivery is represented in Figure 3. Recently, we demonstrated the feasibility of local drug delivery using liposomal verteporfin (Visudyne ${ }^{\circledR}$ ) using ex vivo-perfused atherosclerotic aorta of $\mathrm{ApoE}^{-/-}$mice. ${ }^{74}$ The study highlighted that subsequent intraarterial photoactivation preferentially induces apoptosis of plaque cells. We further confirmed these results in isolated atherosclerotic iliac artery of New Zealand White rabbit. Local application of Visudyne ${ }^{\circledR}$ (2.5 $\mathrm{mg} / \mathrm{mL}$ for 15 minutes) directly over plaques in balloon-injured 


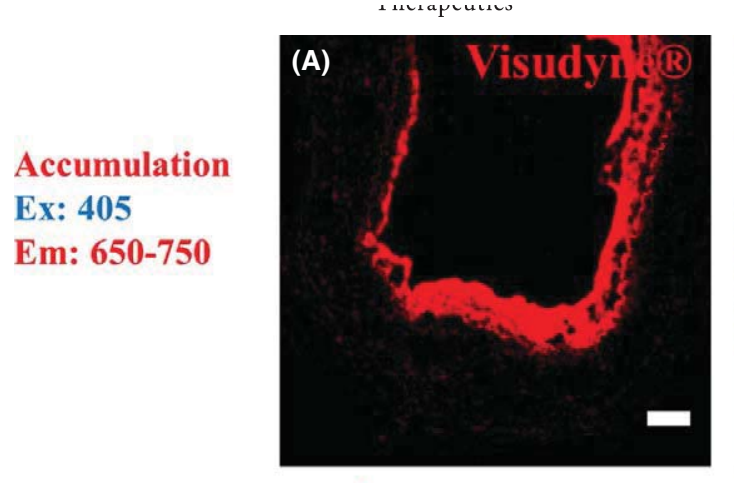

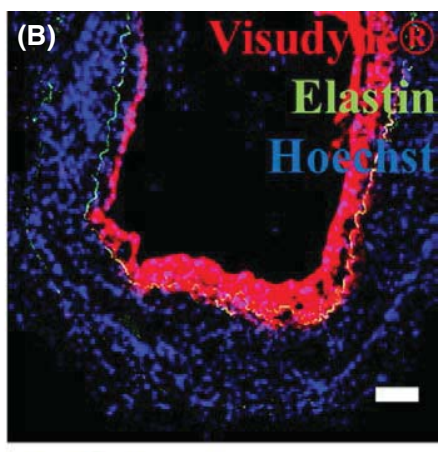
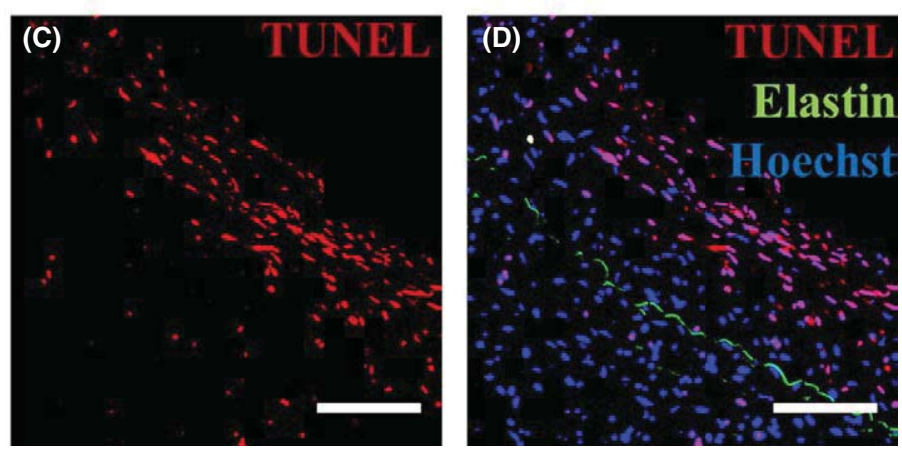

FIGURE 4 Illustration of (A, B) the accumulation of liposomal verteporfin $\left(\right.$ Visudyne ${ }^{\circledR}$ ) following ex vivo perfusion in rabbit atherosclerotic iliac artery and (C, D) intra-arterial PDT-induced apoptosis of plaque cells. Scale bar: $100 \mu \mathrm{m}$ rabbit iliac artery resulted in its preferential accumulation in plaques (Figure 4A and B). Moreover, intraarterial PDT (fluence: $200 \mathrm{~J} / \mathrm{cm}^{2}$, irradiance-334 $\mathrm{mW} / \mathrm{cm}^{2}$ ) applied immediately after Visudyne ${ }^{\circledR}$ perfusion using a cylindrical light diffuser coupled to a diode laser (690 nm) led to an increase in apoptotic cells in the plaque (Figure 4C and D).

Local application of motexafin lutetium in rabbits ${ }^{12}$ or Photofrin in pigs, ${ }^{75}$ rabbits, and human subjects ${ }^{60}$ had been investigated as a means of inducing selective accumulation, localized macrophage apoptosis, or reducing intimal hyperplasia. Local delivery of Photofrin over injured rabbit iliac arteries for 10 minutes resulted in significantly (4.9-fold) higher accumulation compared to that 24 hours after systemic delivery. ${ }^{60}$ No signs of toxicity were noted after local application. Local delivery of motexafin lutetium in rabbits was performed using a drug delivery balloon catheter that was advanced to atherosclerotic iliac artery, and motexafin lutetium was infused directly over the plaque. Local delivery enabled to cut the dose required to one-tenth to that of systemic dose. In all cases, the vessels were illuminated by removing the drug delivery balloon catheters and inserting a laser catheter over the lesion.

\section{0 | NOVEL PHOTOSENSITIZER FOR THERANOSTIC APPLICATION}

Although most of the individual dye molecules mentioned can actually be used for both detection and therapy, current developments focus on activatable photosensitizers with increased specificity with the possibility to target macrophages within the plaque and provide a new generation of theranostic agent. Photosensitizers remain optically silent until they reach the targeted tissue and are light-activated in situ. An example of enzyme-mediated activation of photosensitizer includes protease-mediated drug delivery in which such activity-based compounds contain a specific substrate scaffold in their design. ${ }^{76}$ The feasibility of protease-mediated activation of photosensitizers was presented in an experimental animal model for prostate cancer. ${ }^{77}$

Indeed, plaques are characterized by the presence of highly active macrophages with elevated cathepsin levels and protease activity. These proteases are valuable biomarkers for plaque detection and treatment. Shon and colleagues designed and synthesized atheroma, a new theranostic photosensitizer, and injected living mice with it. The molecule could be cleaved specifically by cathepsin B present in the mouse atheroma. This released the chemical chlorin-e6, which could then be used either to detect or to reduce the plaque activity in the mouse. $^{78}$ The results corroborate other investigations that combined chlorin e6-based photosensitizer with cathepsin B or scavenger recep$\operatorname{tor}^{68,79}$ for selective detection of plaque macrophages. Subsequent photoirradiation of the prodrugs resulted in a decrease in plaque macrophage content and plaque stabilization. Importantly, skin phototoxicity was found to be blunted. ${ }^{78}$

Enzyme-sensitive fluorescent probes may be used as molecular imaging agents. They can provide valuable molecular information on plaque composition. Kim et al. ${ }^{80}$ confirmed clinical benefits of molecular imaging using cathepsin B or matrix metalloproteinase-2/-9 activatable imaging probes in determining vulnerable atherosclerotic plaques from patient tissues. Results from probe activation, in vivo imaging, and histology emphasized that highly stenosed plaques were associated with higher cathepsin B or MMP activity. Availability of high-sensitivity and safe enzyme-sensitive fluorescent probes has enabled new and dynamic insights into the vessel wall for a better understanding of this complex disease. When combined with an invasive near-infrared fluorescence imaging system or noninvasive fluorescent tomography system, photosensitizer accumulation in human carotid plaque may be visualized. ${ }^{81}$ The use of activatable photosensitizer holds interesting potential for diagnosis and treatment of 
vulnerable atherosclerosis lesions in vivo, leading to effective disease management.

\section{1 | THE CHOICE OF THE PHOTOSENSITIZER}

The greatest challenge to make PDT particularly attractive for the treatment of atherosclerosis is to selectively target the plaque without harming the normal vessel wall. Even though a number of photosensitizers were shown to preferentially accumulate in atherosclerotic lesions, the systemic application of these agents is associated with nonspecific localization within the adjacent vessel wall. Extensive research in the field of "targeted-PDT" has created a larger number of "smart" photosensitizers with (1) no dark toxicity, (2) improved selectivity for the plaque macrophages, (3) longer activation wavelengths favoring deep tissue penetration, and (4) features of targeted activation. However, these newer agents still require rather long time to accumulate properly in the lesion. This restricts the use of these agents for the treatment of acute lesions. Another point that needs to be reconsidered is the lack of selectivity toward specific phenotype of plaque macrophages as certain macrophages are involved in plaque stabilization and the depletion might provoke plaque rupture. Photoimmunotherapy, in which a photosensitizer is conjugated with an antibody directed toward specific receptors, is an upcoming field used to improve the recognition specificity of photosensitizer. Although this approach has not been tested for the PDT of atherosclerosis, promising results were obtained for the treatment of cancers. Future PDT must allow development and refinement of more optimal therapeutic agents. The choice of photosensitizer should mainly be made based on the selectivity of uptake in plaque, drug light interval, the yield of triplet state that generates singlet oxygen, and possibly the lack of toxicity. The distribution of the photosensitizer within different compartments of the plaque is likely also very important.

\section{2 | LIGHT SOURCE AND LIGHT DIFFUSERS}

Apart from the general principles underpinning PDT, which are unchanged from location to location, the technical aspects of this treatment can vary greatly. One such aspect pertains to light sources and delivery, which are crucially impacted by the geometry, access, and sterility properties of the target location. This aspect is particularly central to vascular PDT applications.

As small (core diameters in the several hundreds of $\mu \mathrm{m}$ ) optical fibers are usually used in these applications to deliver typically several hundreds of $\mathrm{mW}$ of light following an endovascular route, the natural choice is to use diode laser sources (LEDs) as light emitters. ${ }^{82}$ The main advantage of such laser sources for these applications is that they deliver relatively powerful and bright light beams, which, consequently, can easily be coupled in optical fibers. In addition, such lasers emit light in a narrow spectral domain, thus minimizing illumination duration for a given total light dose. These qualities along with the widespread availability of cheap, reliable easy-to-use semiconductor laser diodes explain why they are ubiquitously selected as illumination sources. ${ }^{83,84}$ It should be noted, however, that each photosensitizer requires relatively specific activation wavelength(s). Thus, the use of such nontunable lasers (at a given wavelength) is limited to photosensitizers that can absorb this wavelength. From a host of manufacturers in the 1990s (Biolitec/Ceramoptec, Bonn, Germany; Modulight, Tampere, Finland; Diomed, Cambridge, UK; Miravant Medical Technologies, CA, USA; Biooptics, Korea), only a handful still commercialize these devices after the suppliers' landscape underwent consolidation during the past decade. Some applications of lightemitting diodes (albeit in different, but similarly shaped organs) are also reported for in situ localization of LEDs, paving the way for local illumination instead of guiding it to the site to be treated and maximizing their (limited) efficiency. ${ }^{85}$

In the specific case of diffusers used for the treatment of atherosclerotic plaque, numerous groups active in the field use fiber-based diffusers, passed through catheters. Indeed, pragmatism indicates that the best way to achieve suitable illumination is through endovascular light delivery, using a cylindrical (radial) diffuser such as the one described in Figure 5 or that described by Mizeret et al. ${ }^{86}$ In all instances, the goal is to achieve homogenous light delivery without temperature increase in order to maximize the photodynamic effects while avoiding possibly deleterious thermal effects or other side effects. ${ }^{84}$ Generally, however, radial/cylindrical diffusers offer an interesting way to deliver intravascular illumination for the treatment of acute coronary syndromes and regional atherosclerosis, ${ }^{11,62}$ especially for plaque stabilization, as opposed to plaque ablation. As these 10to $40-\mathrm{mm}$-long cylindrical light-emitting distributors are frequently introduced in the treated vessel through a catheter, caution must be exercised to ensure that the illumination profile of the diffuser is not modified by the catheter's material. ${ }^{87,88}$ Similar caution must be

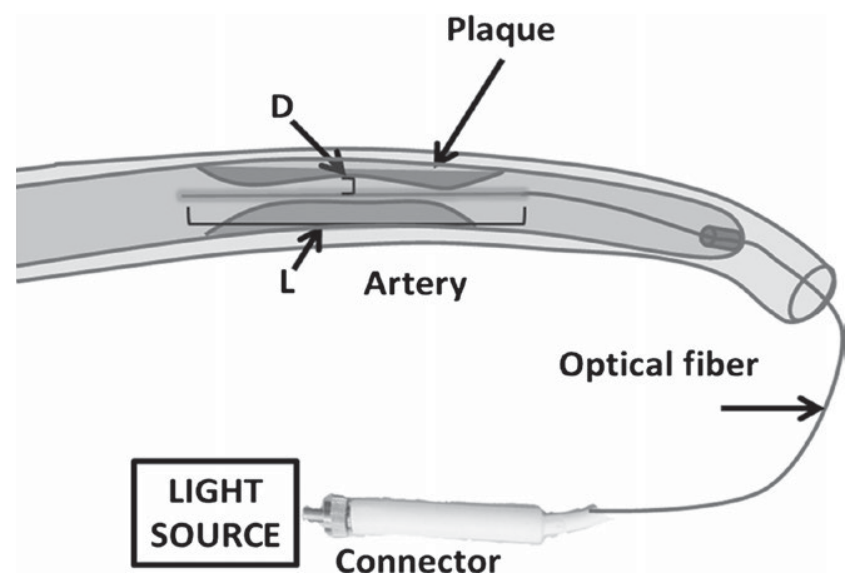

FIGURE 5 Intraarterial photoactivation: Cylindrical light diffuser is connected to light source via optical connector. At the end of the fiber is an illumination tip with length L, which homogenously distributes the light along its length. The light diffuser alone or coupled to balloon catheter is guided over the plaque for endovascular illumination. $\mathrm{D}$ is the distance between the diffuser surface and the vessel wall 
exercised when the light distributor is centered within the vessel's lumen with an inflatable balloon. This approach is particularly appropriate when the fiber diameter is much smaller than the lumen diameter. Balloon catheters provide the benefit to interrupt blood flow and to remove blood from the illuminated surface, features that are sometimes used intermittently. ${ }^{41,57}$ As it helps minimizing blood presence in the treated areas, the absorption of the excitation light used for PDT is decreased. ${ }^{89}$ As the blood flow interruption is limited in duration, this feature of balloon catheters can be a disadvantage (limited total delivered light dose) or an advantage (limited risk of side effects) ${ }^{90}$ It should be noted that the duration of this interruption can be significantly increased using "perfusion catheters" that are designed so that the blood flow is not totally interrupted when the balloon is inflated.

Instances are reported ${ }^{91}$ when the PDT effect described is too weak, a side effect that can be ascribed to the blood absorption of light. ${ }^{91-93}$ In the case of a diffuser such as the one described in Figure 5, it must illuminate with a profile as close as possible to a perfect cylinder. ${ }^{94,95}$ Thus, at a given distance from the diffuser, the exact light dose delivered as primary incidence can be computed as long as $d \ll L$ (with $d=$ the distance between the diffuser surface and the vessel wall, and $L=$ the irradiation length of the diffuser; see Figure 5). This distance " $d$ " is an important parameter not only because it affects the irradiance as the illuminated surface is equal to $2 \pi d L$, but also because it has an influence on the shape of the illumination spot. ${ }^{95-97}$ It is important to note that additional features of good light distributors are that they do not compress the organ, which would result in a reduction in the perfusion and suboptimal PDT results. They must also display suitable mechanical properties such as flexibility, ${ }^{88}$ pushability, and being easy to position (guide wire, $\mathrm{X}$-ray markers). Some distributors even include features such as monitoring of fiber rupture using back-reflected light. ${ }^{98}$ Finally, it should be noted that the plaque itself frequently presents optical properties that are not only heterogeneous but also significantly different than those of the normal surrounding tissues. ${ }^{99}$ As these optical properties cannot realistically be determined before each treatment, one reasonable strategy is to adjust the light dosimetry on the basis of the type of plaque to be treated.

\section{3 | CHALLENGES FOR CLINICAL TRANSLATION OF PDT AND MAJOR IMPROVEMENT OVER TIME}

Photodynamic therapy for the treatment of atherosclerosis and restenosis after angioplasty was a subject extensively investigated in the medical and academic fields, mainly between 1990 and 2000. This is about at the end of this period that the important industrial developments conducted by pharmaceutical and medtech companies, including Pharmacyclics and Miravant, have been stopped. Therefore, these applications of PDT almost completely dropped out of consideration in the academic field in recent years. This situation is surprising considering the numerous, globally very positive, reports published up to now about PDT by both academic centers and industries. Many factors can explain this evolution. They can be classified into two
TABLE 2 Illustration of the major issues that diminished the interest of photodynamic therapy (PDT) for atherosclerosis and major improvements over time

\begin{tabular}{ll}
$\begin{array}{l}\text { Issues that diminished the } \\
\text { interest in PDT of atheroma }\end{array}$ & $\begin{array}{l}\text { Major improvements in PDT } \\
\text { procedure }\end{array}$ \\
$\begin{array}{ll}\text { - Difficulties in regulatory } \\
\text { approval }\end{array}$ & $\begin{array}{l}\text { - FDA approved PDT protocol } \\
\text { (treatment of ARMD using }\end{array}$ \\
- Cutaneous phototoxic & Visudyne is approved) \\
reactions following PDT & - Minor and self-limiting \\
procedure & cutaneous phototoxicity \\
- Nonselective nature of PSs & - Development of targeted PSs \\
- Long DLI and illumination time & with high specificity \\
- PSs having low absorption & - Short DLI using local delivery \\
wavelength cannot be & approach \\
activated in the presence of & - New-generation PSs have \\
blood & long absorption wavelength \\
- Bulky and less powerful light & and can be activated in the \\
delivery devices & presence of blood \\
- Invasive procedure for & - Development of compact and \\
intravascular illumination & powerful lasers and light \\
& distributers \\
\hline
\end{tabular}

categories: (1) environmental, and (2) technology associated with "photosensitizer" or "light delivery devices" in terms of performance, side effects, costs, etc. (Table 2).

The first category, which certainly played the most important role in the marked reduction of activities in the field of PDT in cardiology, involved the following:

1. Strategy changes of key companies during the course of their clinical development either due to either (1) the success of drug-releasing stents in the cardiovascular field when the pharmaceutical companies active in the development of PDT were conducting, or were about to launch, their phase I and II clinical trials, or (2) the decision of pharma companies to focus, for one reason or the other, on most of the resources on the development of other lead molecules; for instance, Pharmacyclics decided to focus on the development of Xcytrin for treating brain metastases (K. Woodburn, personal communication), which turned out to be very important drains of resources. A redefinition, during the course of the developments of PDT in cardiology, of its medical applications is required as this approach seems to be more appropriate for plaque stabilization, as opposed to plaque ablation or prevention of restenosis. ${ }^{11,100}$

2. The increasing importance of the burden generated by the regulation which, in particular in the United States, has become quite complex for therapies based on both medtech and pharma technologies. This was the case until the US FDA's acceptance of Visudyne for the PDT of wet age-related macular degeneration (ARMD), which was a real game changer in ophthalmology, with millions of patients that have now had this sight-saving therapy.

In addition, the technology challenges involves the following: (1) incidence of cutaneous phototoxic reactions observed during the few clinical studies addressing PDT in cardiology ${ }^{28,59}$; (2) lack of treatment selectivity 
where it was not clear whether PDT-mediated destruction of macrophages, smooth muscle cells, or fibroblast would always be beneficial or it may lead to thinning of fibrous cap or increase the formation of necrotic core due to killing of macrophage foam cell. PDT-induced ROS and apoptotic cells in the plaque can also eventually increase plaque vulnerability in the long term; (3) an administration of the photosensitizers between 8 and 24 hours before the intervention, a problematic constraint in terms of patient management, in particular because it hinders the uses of PDT in acute coronary syndromes; and (4) in some cases, such as the Miravant drug MV0611, one had to remove blood around the catheter, as the blood absorbed the wavelength used to excite that drug.

The constraints associated with the "light delivery technology" that hindered the clinical use of PDT include the following: (1) the relatively long (10 minutes or more) illumination which slows the catheterization procedure; and (2) an intravascular illumination limiting its use during invasive procedures.

Major improvement has been performed since the first application of PDT for atherosclerosis. It should be noted that the vast majority of the environmental and technological problems or drawbacks mentioned above have been solved. New generations of photosensitizers with higher specificity, more homogenous distributions within the plaque, and local intravascular drug and light delivery technologies diminished adverse effects and support a regain of interest for PDT. Local delivery approach dramatically reduces contact time and diminishes adverse effects thus supporting the feasibility of PDT under clinical settings. ${ }^{74}$ The development of new "perfusion balloon catheters" allows for effective local drug delivery over short periods of time using very high drug concentrations followed by local light delivery. During such PDT interventions, the new catheters permit blood to flow through a separate channel in the double-balloon construct. The local delivery of the drug and the light with these new catheters eliminates essentially all problems summarized above that were due to the insufficient drug/light selectivity. However, some unresolved issues still pose a question mark for clinical use of PDT including troubles in optimization of multiple PDT components (ie, drug and light dose, DLI), prediction of the PDT response, insufficient clinical data, lack of follow-up protocol, and financial constraints in setting up PDT laboratory. It is possible that PDT in combination with other forms of treatment may permit low doses of the concomitant therapies in the hope of decreasing their side effects. In sum, in worrying about cardiovascular events subsequent to the stenting of the "culprit" lesion, intracoronary PDT treatment of the inflamed nonstenotic atheromas that might be the cause of such secondary events could possibly be a therapy of choice, in particular if such lesions would represent quite long regions of "vulnerable" plaque.

\section{4 | CLINICAL PERSPECTIVES}

Performing balloon angioplasty and stent deployment is certainly the prime choice while dealing with patient having a severe blockage that could result in myocardial infarction or sudden death if not ameliorated.
Two potential applications of the PDT can be envisioned. First is the treatment of secondary vulnerable plaques. After stenting, approximately $14 \%$ of patients experience plaque ruptures that are considered nonculprit at the time of the initial procedure. ${ }^{101}$ The progression of untreated vulnerable coronary plaques remains major burdens. Recently, the detection of vulnerable plaque has greatly improved and preventive local intervention will then be required. No preventive treatment exists at the moment. As PDT could provoke plaque stabilization, these vulnerable plaques might be a reasonable target for PDT. PDT can be integrated into conventional $\mathrm{PCl}$ procedures and is best suited to stabilize vulnerable plaques. In addition, systemic photosensitizer administration allows treating multiple vessel segments within a single intervention. The second application of PDT would be for the prevention of "neoatherosclerosis." Neoatherosclerosis is emerging as a new coronary-stent-associated problem with the use of new secondgeneration drug-eluting stents that help to seal the atherosclerotic lesions but also result in delayed reendothelialization, recruitment of macrophages, and proliferation of the neointima within the stented segment. ${ }^{102}$ The capability of PDT to provoke plaque stabilization could be utilized to prevent rupture of such neoatherosclerotic lesions. Although the advent of second-generation DES substantially reduced the risk for in-stent restenosis, neither first- nor second-generation DES is resistant to restenosis. Combining PDT immediately after percutaneous coronary intervention may prevent the recurrence of stent-induced restenosis.

In conclusion, PDT would favor both identification and stabilization/regression of vulnerable plaque in both types of lesions (de novo and neoatherogenic).

\section{ETHICS}

Animal experimental protocol dealing with New Zealand rabbits was approved by the Cantonal Veterinary Office, Fribourg, and the Swiss Federal Veterinary Office, Switzerland (FR 2015/58).

\section{AUTHOR CONTRIBUTION}

MJ, MZ, HV, GW, SC, and MNG contributed to design, drafting, and revision of article. All authors approved the final version of manuscript for publication and agree to be accountable for all aspects of the work.

\section{ACKNOWLEDGMENTS}

We thank Prof. David Kessel and Dr. Kathryn Woodburn for helpful discussions. We are grateful to Dr. Norbert Lange from School of Pharmaceutical Sciences, University of Geneva, Switzerland, for providing specific inputs into the project.

\section{DATA SOURCES}

A systematic review was performed to address the applicability of PDT for the treatment of atherosclerotic plaques. Searches were conducted in the PubMed/Medline, Google Scholar, and Web of Science using combinations of the following key words: PDT, imaging, 
atherosclerosis, plaque, restenosis, intimal hyperplasia, macrophage, angioplasty, theranostic, photosensitizers, hematoporphyrin derivative, Photofrin, phthalocyanines, talaporfin sodium, verteporfin, 5 -aminolevulinic acid, and motexafin lutetium. No restrictions were used for the search string. Cross-references were also carried out on the articles retrieved.

\section{CONFLICT OF INTERESTS}

GW is a shareholder of Medlight SA.

\section{REFERENCES}

1. Cook S. Heart rate, coronary artery disease and plaque rupture myth, hype, or truth? Swiss Med Wkly. 2012;142:w13661.

2. Cook S, Hess OM. Resting heart rate and cardiovascular events: time for a new crusade? Eur Heart J. 2010;31:517-519.

3. Go AS, Mozaffarian D, Roger VL, et al. Executive summary: heart disease and stroke statistics-2013 update: a report from the American Heart Association. Circulation. 2013;127:143-152.

4. Ridker PM, Cannon CP, Morrow D, et al. C-reactive protein levels and outcomes after statin therapy. N Engl J Med. 2005;352:20-28.

5. Cannon $\mathrm{CP}$, Braunwald E, McCabe $\mathrm{CH}$, et al. Intensive versus moderate lipid lowering with statins after acute coronary syndromes. N Engl J Med. 2004;350:1495-1504.

6. Gupta A, Wang Y, Spertus JA, et al. Trends in acute myocardial infarction in young patients and differences by sex and race, 2001 to 2010. J Am Coll Cardiol. 2014;64:337-345.

7. Gogas BD, McDaniel M, Samady H, King SB 3rd. Novel drugeluting stents for coronary revascularization. Trends Cardiovasc Med. 2014;24:305-313.

8. Kuchulakanti PK, Chu WW, Torguson R, et al. Correlates and long-term outcomes of angiographically proven stent thrombosis with sirolimus- and paclitaxel-eluting stents. Circulation. 2006;113:1108-1113.

9. Michaels AD, Chatterjee K. Cardiology patient pages. Angioplasty versus bypass surgery for coronary artery disease. Circulation. 2002;106:e187-e190.

10. Fisher CM, Fletcher JP, May J, et al. No additional benefit from laser in balloon angioplasty of the superficial femoral artery. Eur J Vasc Endovasc Surg. 1996;11:349-352.

11. Waksman R, McEwan PE, Moore TI, et al. PhotoPoint photodynamic therapy promotes stabilization of atherosclerotic plaques and inhibits plaque progression. J Am Coll Cardiol. 2008;52:1024-1032.

12. Hayase M, Woodbum KW, Perlroth J, et al. Photoangioplasty with local motexafin lutetium delivery reduces macrophages in a rabbit post-balloon injury model. Cardiovasc Res. 2001;49:449-455.

13. Chen Z, Woodburn KW, Shi C, et al. Photodynamic therapy with motexafin lutetium induces redox-sensitive apoptosis of vascular cells. Arterioscler Thromb Vasc Biol. 2001;21:759-764.

14. Mroz P, Yaroslavsky A, Kharkwal GB, Hamblin MR. Cell death pathways in photodynamic therapy of cancer. Cancers (Basel). 2011;3:2516-2539.

15. Glick D, Barth S, Macleod KF. Autophagy: cellular and molecular mechanisms. J Pathol. 2010;221:3-12.

16. Granville DJ, Cassidy BA, Ruehlmann DO, et al. Mitochondrial release of apoptosis-inducing factor and cytochrome $\mathrm{c}$ during smooth muscle cell apoptosis. Am J Pathol. 2001;159:305-311.

17. Oleinick NL, Morris RL, Belichenko I. The role of apoptosis in response to photodynamic therapy: what, where, why, and how. Photochem Photobiol Sci. 2002;1:1-21.

18. Zheng Y, Yin G, Le $V$, et al. Photodynamic-therapy activates immune response by disrupting immunity homeostasis of tumor cells, which generates vaccine for cancer therapy. Int J Biol Sci. 2016;12:120-132.
19. Allison BA, Crespo MT, Jain AK, et al. Delivery of benzoporphyrin derivative, a photosensitizer, into atherosclerotic plaque of Watanabe heritable hyperlipidemic rabbits and balloon-injured New Zealand rabbits. Photochem Photobiol. 1997;65:877-883.

20. Spears JR, Serur J, Shropshire D, Paulin S. Fluorescence of experimental atheromatous plaques with hematoporphyrin derivative. $J$ Clin Invest. 1983;71:395-399.

21. Spokojny AM, Serur JR, Skillman J, Spears JR. Uptake of hematoporphyrin derivative by atheromatous plaques: studies in human in vitro and rabbit in vivo. J Am Coll Cardiol. 1986;8:1387-1392.

22. Usui M, Asahara T, Naitoh $\mathrm{Y}$, Katoh T, Ibukiyama C. Photodynamic therapy for the prevention of intimal hyperplasia in balloon-injured rabbit arteries. Jpn Circ J. 1999;63:387-393.

23. Hsiang YN, Todd ME, Bower RD. Determining light dose for photodynamic therapy of atherosclerotic lesions in the Yucatan miniswine. J Endovasc Surg. 1995;2:365-371.

24. Cheung J, Todd M, Turnbull R, et al. Longer term assessment of photodynamic therapy for intimal hyperplasia: a pilot study. J Photochem Photobiol, B. 2004;73:141-147.

25. Hsiang YN, Fragoso M, Tsang V, Schreiber WE. Determining the optimal dose of Photofrin in miniswine atherosclerotic plaque. Photochem Photobiol. 1993;57:518-525.

26. Amemiya $\mathrm{T}$, Nakajima $\mathrm{H}$, Katoh $\mathrm{T}$, et al. Photodynamic therapy of atherosclerosis using YAG-OPO laser and Porfimer sodium, and comparison with using argon-dye laser. Jpn Circ J. 1999;63:288-295.

27. Wooten RS, Smith KC, Ahlquist DA, Muller SA, Balm RK. Prospective study of cutaneous phototoxicity after systemic hematoporphyrin derivative. Lasers Surg Med. 1988;8:294-300.

28. Dougherty TJ, Cooper MT, Mang TS. Cutaneous phototoxic occurrences in patients receiving Photofrin. Lasers Surg Med. 1990;10:485-488.

29. Hsiang YN, Crespo MT, Richter AM, et al. In vitro and in vivo uptake of benzoporphyrin derivative into human and miniswine atherosclerotic plaque. Photochem Photobiol. 1993;57:670-674.

30. Eldar M, Yerushalmi $Y$, Kessler E, et al. Preferential uptake of a water-soluble phthalocyanine by atherosclerotic plaques in rabbits. Atherosclerosis. 1990;84:135-139.

31. Mir Y, van Lier JE, Paquette B, Houde D. Oxygen dependence of twophoton activation of zinc and copper phthalocyanine tetrasulfonate in Jurkat cells. Photochem Photobiol. 2008;84:1182-1186.

32. Muragaki $\mathrm{Y}$, Akimoto J, Maruyama T, et al. Phase II clinical study on intraoperative photodynamic therapy with talaporfin sodium and semiconductor laser in patients with malignant brain tumors. $J$ Neurosurg. 2013;119:845-852.

33. Hayashi J, Saito T, Sato H, Kuroiwa Y, Aizawa K. Direct visualization of atherosclerosis in small coronary arteries using the epifluorescence stereoscope. Cardiovasc Res. 1995;30:775-780.

34. Nagae T, Aizawa K, Uchimura N, et al. Endovascular photodynamic therapy using mono-L-aspartyl-chlorin e6 to inhibit Intimal hyperplasia in balloon-injured rabbit arteries. Lasers Surg Med. 2001;28:381-388.

35. Hayashi J, Saito T, Aizawa K. Photodynamic diagnosis and treatment for atherosclerosis by an endoscopic approach. Diagn Ther Endosc. 1999:5:191-195.

36. Yamaguchi A, Woodburn KW, Hayase M, Hoyt G, Robbins RC. Photodynamic therapy with motexafin lutetium (Lu-Tex) reduces experimental graft coronary artery disease. Transplantation. 2001;71:1526-1532.

37. Yamaguchi A, Woodburn KW, Hayase M, Robbins RC. Reduction of vein graft disease using photodynamic therapy with motexafin lutetium in a rodent isograft model. Circulation 2000;102(19 Suppl 3):III275-III280.

38. Woodburn KW, Fan Q, Kessel D, et al. Phototherapy of cancer and atheromatous plaque with texaphyrins. J Clin Laser Med Surg. 1996;14:343-348. 
39. Peng C, Li Y, Liang H, et al. Detection and photodynamic therapy of inflamed atherosclerotic plaques in the carotid artery of rabbits. $J$ Photochem Photobiol, B. 2011;102:26-31.

40. Pai M, Jamal W, Mosse A, et al. Inhibition of in-stent restenosis in rabbit iliac arteries with photodynamic therapy. Eur J Vasc Endovasc Surg. 2005;30:573-581.

41. Jenkins MP, Buonaccorsi GA, Mansfield R, et al. Reduction in the response to coronary and iliac artery injury with photodynamic therapy using 5-aminolaevulinic acid. Cardiovasc Res. 2000;45: 478-485.

42. Jenkins MP, Buonaccorsi G, MacRobert A, et al. Intra-arterial photodynamic therapy using 5-ALA in a swine model. Eur J Vasc Endovasc Surg. 1998;16:284-291.

43. Kwon OC, Yoon HJ, Kim KH, et al. Fluorescence kinetics of protoporphyrin-IX induced from 5-ALA compounds in rabbit postbalIoon injury model for ALA-photoangioplasty. Photochem Photobiol. 2008;84:1209-1214.

44. Kim H, Kim Y, Kim IH, Kim K, Choi Y. ROS-responsive activatable photosensitizing agent for imaging and photodynamic therapy of activated macrophages. Theranostics. 2013;4:1-11.

45. Zhu X, Wang H, Zheng L, et al. Upconversion nanoparticle-mediated photodynamic therapy induces THP-1 macrophage apoptosis via ROS bursts and activation of the mitochondrial caspase pathway. Int J Nanomedicine. 2015;10:3719-3736.

46. Hayashi N, Kataoka $\mathrm{H}$, Yano $\mathrm{S}$, et al. A novel photodynamic therapy targeting cancer cells and tumor-associated macrophages. $\mathrm{Mol}$ Cancer Ther. 2015;14:452-460.

47. Dartsch PC, Wunderlich K, Ben-Hur E. Aluminium phthalocyaninesinduced photolysis of human vascular wall cells in culture and the effect of fluoride on photodynamic action. Coron Artery Dis. 1994; 5:851-855.

48. Statius van Eps RG, Adili F, Watkins MT, Anderson RR, LaMuraglia GM. Photodynamic therapy of extracellular matrix stimulates endothelial cell growth by inactivation of matrix-associated transforming growth factor-beta. Lab Invest. 1997;76:257-266.

49. Ortu P, LaMuraglia GM, Roberts WG, Flotte TJ, Hasan T. Photodynamic therapy of arteries. A novel approach for treatment of experimental intimal hyperplasia. Circulation. 1992;85:1189-1196.

50. Statius van Eps RG, ChandraSekar NR, Hasan T, LaMuraglia GM. Importance of the treatment field for the application of vascular photodynamic therapy to inhibit intimal hyperplasia. Photochem Photobiol. 1998;67:337-342.

51. Statius van Eps RG, Adili F, LaMuraglia GM. Photodynamic therapy inactivates cell-associated basic fibroblast growth factor: a silent way of vascular smooth muscle cell eradication. Cardiovasc Res. 1997;35:334-340.

52. LaMuraglia GM, ChandraSekar NR, Flotte TJ, et al. Photodynamic therapy inhibition of experimental intimal hyperplasia: acute and chronic effects. J Vasc Surg. 1994;19:321-329; discussion 9-31.

53. Nyamekye I, Buonaccorsi G, McEwan J, et al. Inhibition of intimal hyperplasia in balloon injured arteries with adjunctive phthalocyanine sensitised photodynamic therapy. Eur J Vasc Endovasc Surg. 1996;11:19-28.

54. Adili F, Statius van Eps RG, Flotte TJ, LaMuraglia GM. Photodynamic therapy with local photosensitizer delivery inhibits experimental intimal hyperplasia. Lasers Surg Med. 1998;23:263-273.

55. Wakamatsu T, Saito T, Hayashi J, et al. Long-term inhibition of intimal hyperplasia using vascular photodynamic therapy in balloon-injured carotid arteries. Med Mol Morphol. 2005;38:225-232.

56. Nyamekye I, Anglin S, McEwan J, et al. Photodynamic therapy of normal and balloon-injured rat carotid arteries using 5-amino-levulinic acid. Circulation. 1995;91:417-425.

57. Jenkins MP, Buonaccorsi GA, Raphael M, et al. Clinical study of adjuvant photodynamic therapy to reduce restenosis following femoral angioplasty. Br J Surg. 1999;86:1258-1263.
58. Rockson SG, Kramer P, Razavi M, et al. Photoangioplasty for human peripheral atherosclerosis: results of a phase I trial of photodynamic therapy with motexafin lutetium (Antrin). Circulation. 2000;102:2322-2324.

59. Kereiakes DJ, Szyniszewski AM, Wahr D, et al. Phase I drug and light dose-escalation trial of motexafin lutetium and far red light activation (phototherapy) in subjects with coronary artery disease undergoing percutaneous coronary intervention and stent deployment: procedural and long-term results. Circulation. 2003;108:1310-1315.

60. Usui M, Miyagi M, Fukasawa S, et al. A first trial in the clinical application of photodynamic therapy for the prevention of restenosis after coronary-stent placement. Lasers Surg Med. 2004;34:235-241.

61. Tang G, Hyman S, Schneider JH Jr., Giannotta SL. Application of photodynamic therapy to the treatment of atherosclerotic plaques. Neurosurgery. 1993;32:438-443; discussion 43.

62. Waksman R, Leitch IM, Roessler J, et al. Intracoronary photodynamic therapy reduces neointimal growth without suppressing reendothelialisation in a porcine model. Heart. 2006;92:1138-1144.

63. Hsiang YN, Crespo MT, Machan LS, Bower RD, Todd ME. Photodynamic therapy for atherosclerotic stenoses in Yucatan miniswine. Can J Surg. 1994;37:148-152.

64. Kolodgie FD, Katocs AS Jr, Largis EE, et al. Hypercholesterolemia in the rabbit induced by feeding graded amounts of low-level cholesterol. Methodological considerations regarding individual variability in response to dietary cholesterol and development of lesion type. Arterioscler Thromb Vasc Biol. 1996;16:1454-1464.

65. Singh V, Tiwari RL, Dikshit M, Barthwal MK. Models to study atherosclerosis: a mechanistic insight. Curr Vasc Pharmacol. 2009;7: 75-109.

66. Braathen LR. Photodynamic therapy: increasing acceptance through reduction of adverse reactions. Br J Dermatol. 2014;171:1298-1299.

67. McCarthy JR, Korngold E, Weissleder R, Jaffer FA. A light-activated theranostic nanoagent for targeted macrophage ablation in inflammatory atherosclerosis. Small. 2010;6:2041-2049.

68. Tawakol A, Castano AP, Anatelli F, et al. Photosensitizer delivery to vulnerable atherosclerotic plaque: comparison of macrophagetargeted conjugate versus free chlorin(e6). J Biomed Opt. 2006;11: 021008.

69. Kang YS, Kim JY, Bruening SA, et al. The C-type lectin SIGN-R1 mediates uptake of the capsular polysaccharide of Streptococcus pneumoniae in the marginal zone of mouse spleen. Proc Natl Acad Sci USA. 2004;101:215-220.

70. Taylor PR, Brown GD, Herre J, et al. The role of SIGNR1 and the betaglucan receptor (dectin-1) in the nonopsonic recognition of yeast by specific macrophages. J Immunol. 2004;172:1157-1162.

71. de Oliveira Goncalves K, da Silva MN, Sicchieri LB, et al. Aminolevulinic acid with gold nanoparticles: a novel theranostic agent for atherosclerosis. Analyst. 2015;140:1974-1980.

72. Visona A, Jori G. Targeting of experimentally induced atherosclerotic lesions by liposome-delivered $\mathrm{Zn}(\mathrm{II})$-phthalocyanine. Atherosclerosis. 1993;100:213-222.

73. Gonschior P, Pahl C, Huehns TY, et al. Comparison of local intravascular drug-delivery catheter systems. Am Heart J. 1995;130:1174-1181.

74. Jain $M$, Zellweger $M$, Frobert $A$, et al. Intra-arterial drug and light delivery for photodynamic therapy using Visudyne(R): implication for atherosclerotic plaque treatment. Front Physiol. 2016;7:400.

75. Valassis G, Pragst I, Adolfs C, et al. Local photodynamic therapy reduces tissue hyperplasia after stenting in an experimental restenosis model. Basic Res Cardiol. 2002;97:132-136.

76. Gabriel D, Zuluaga MF, van den Bergh H, Gurny R, Lange N. It is all about proteases: from drug delivery to in vivo imaging and photomedicine. Curr Med Chem. 2011;18:1785-1805.

77. Zuluaga MF, Gabriel D, Lange N. Enhanced prostate cancer targeting by modified protease sensitive photosensitizer prodrugs. Mol Pharm. 2012;9:1570-1579. 
78. Shon SM, Choi Y, Kim JY, et al. Photodynamic therapy using a protease-mediated theranostic agent reduces cathepsin-B activity in mouse atheromata in vivo. Arterioscler Thromb Vasc Biol. 2013;33: 1360-1365.

79. Hamblin MR, Miller JL, Ortel B. Scavenger-receptor targeted photodynamic therapy. Photochem Photobiol. 2000;72:533-540.

80. Kim DE, Kim JY, Schellingerhout D, et al. Protease imaging of human atheromata captures molecular information of atherosclerosis, complementing anatomic imaging. Arterioscler Thromb Vasc Biol. 2010;30:449-456.

81. Mo W, Rohrbach D, Sunar U. Imaging a photodynamic therapy photosensitizer in vivo with a time-gated fluorescence tomography system. J Biomed Opt. 2012;17:071306.

82. Chou TM, Woodburn KW, Cheong WF, et al. Photodynamic therapy: applications in atherosclerotic vascular disease with motexafin lutetium. Catheter Cardiovasc Interv. 2002;57:387-394.

83. Wieman TJ. Lasers and the surgeon. Am J Surg. 1986;151: 493-500.

84. Borshch VN, Andreeva ER, Kuz'min SG, Vozovikov IN. New medicines and approaches to treatment of atherosclerosis. Russ J Gen Chem. 2012;82:554-563.

85. Baran TM, Mironov O, Sharma AK, Foster TH. Indwelling stent embedded with light-emitting diodes for photodynamic therapy of malignant biliary obstruction. Cardiovasc Intervent Radiol. 2016;39:916-919.

86. Mizeret JC, van den Bergh HE. Cylindrical fiberoptic light diffuser for medical applications. Lasers Surg Med. 1996;19:159-167.

87. Dwyer PJ, White WM, Fabian RL, Anderson RR. Optical integrating balloon device for photodynamic therapy. Lasers Surg Med. 2000;26:58-66.

88. van den Bergh $\mathrm{H}$. On the evolution of some endoscopic light delivery systems for photodynamic therapy. Endoscopy. 1998;30:392-407.

89. Vincent GM, Fox J, Charlton G, et al. Presence of blood significantly decreases transmission of $630 \mathrm{~nm}$ laser light. Lasers Surg Med. 1991;11:399-403.

90. Mansfield R, Bown S, McEwan J. Photodynamic therapy: shedding light on restenosis. Heart. 2001;86:612-618.

91. Rockson SG, Lorenz DP, Cheong WF, Woodburn KW. Photoangioplasty: an emerging clinical cardiovascular role for photodynamic therapy. Circulation. 2000;102:591-596.
92. Vincent GM, Mackie RW, Orme E, Fox J, Johnson M. In vivo photosensitizer-enhanced laser angioplasty in atherosclerotic Yucatan miniswine. J Clin Laser Med Surg. 1990;8:59-61.

93. Litvack F, Grundfest WS, Forrester JS, et al. Effects of hematoporphyrin derivative and photodynamic therapy on atherosclerotic rabbits. Am J Cardiol. 1985;56:667-671.

94. Ripley PM, MacRobert AJ, Mills TN, Bown SG. A comparative optical analysis of cylindrical diffuser fibres for laser therapy using fluorescence imaging. Laser Med Sci. 1999;14:257-268.

95. Vesselov LM, Whittington W, Lilge L. Performance evaluation of cylindrical fiber optic light diffusers for biomedical applications. Lasers Surg Med. 2004;34:348-351.

96. Lilge L, Vesselov L, Whittington W. Thin cylindrical diffusers in multimode Ge-doped silica fibers. Lasers Surg Med. 2005;36:245-251.

97. Farina B, Saponaro S, Pignoli E, Tomatis S, Marchesini R. Monte Carlo simulation of light fluence in tissue in a cylindrical diffusing fibre geometry. Phys Med Biol. 1999;44:1-11.

98. Sroka R, Beyer W, Krug M, et al. Laser-light application and light monitoring for photodynamic therapy in hollow organs. Laser Med Sci. 1993;8:63-68.

99. Prince MR, Deutsch TF, Mathews-Roth MM, et al. Preferential light absorption in atheromas in vitro. Implications for laser angioplasty. J Clin Invest. 1986;78:295-302.

100. Muller JE. New light on an old problem photodynamic therapy for atherosclerosis. J Am Coll Cardiol. 2008;52:1033-1034.

101. Xie Y, Mintz GS, Yang J, et al. Clinical outcome of nonculprit plaque ruptures in patients with acute coronary syndrome in the PROSPECT study. JACC Cardiovasc Imaging. 2014;7:397-405.

102. Komiyama H, Takano M, Hata N, et al. Neoatherosclerosis: coronary stents seal atherosclerotic lesions but result in making a new problem of atherosclerosis. World J Cardiol. 2015;7:776-783. 